\title{
8
}
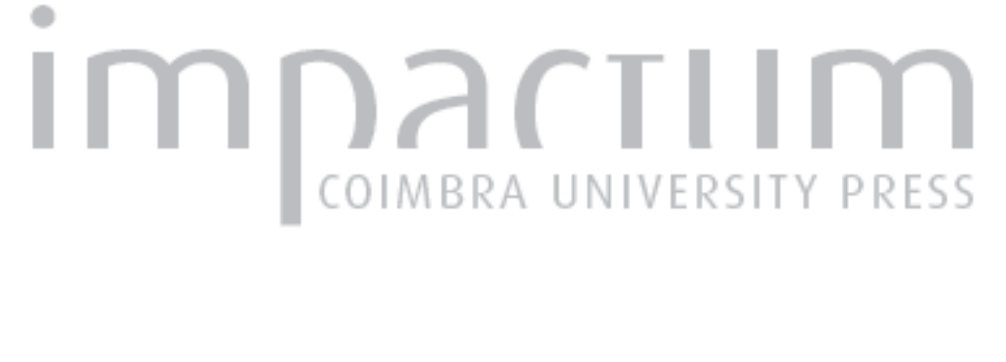

\section{O Seminário de Jesus, Maria e José de Coimbra: um projeto de Giuseppe Antonio}

Landi

Autor(es): $\quad$ Lobo, Rui; Raggi, Giuseppina

Publicado por: Imprensa da Universidade de Coimbra

URL persistente:

URI:http://hdl.handle.net/10316.2/44975

DOI:

DOI:https://doi.org/10.14195/0870-8584_12_12

Accessed : $\quad$ 26-Apr-2023 02:44:04

A navegação consulta e descarregamento dos títulos inseridos nas Bibliotecas Digitais UC Digitalis, UC Pombalina e UC Impactum, pressupõem a aceitação plena e sem reservas dos Termos e Condições de Uso destas Bibliotecas Digitais, disponíveis em https://digitalis.uc.pt/pt-pt/termos.

Conforme exposto nos referidos Termos e Condições de Uso, o descarregamento de títulos de acesso restrito requer uma licença válida de autorização devendo o utilizador aceder ao(s) documento(s) a partir de um endereço de IP da instituição detentora da supramencionada licença.

Ao utilizador é apenas permitido o descarregamento para uso pessoal, pelo que o emprego do(s) título(s) descarregado(s) para outro fim, designadamente comercial, carece de autorização do respetivo autor ou editor da obra.

Na medida em que todas as obras da UC Digitalis se encontram protegidas pelo Código do Direito de Autor e Direitos Conexos e demais legislação aplicável, toda a cópia, parcial ou total, deste documento, nos casos em que é legalmente admitida, deverá conter ou fazer-se acompanhar por este aviso.

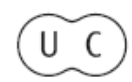




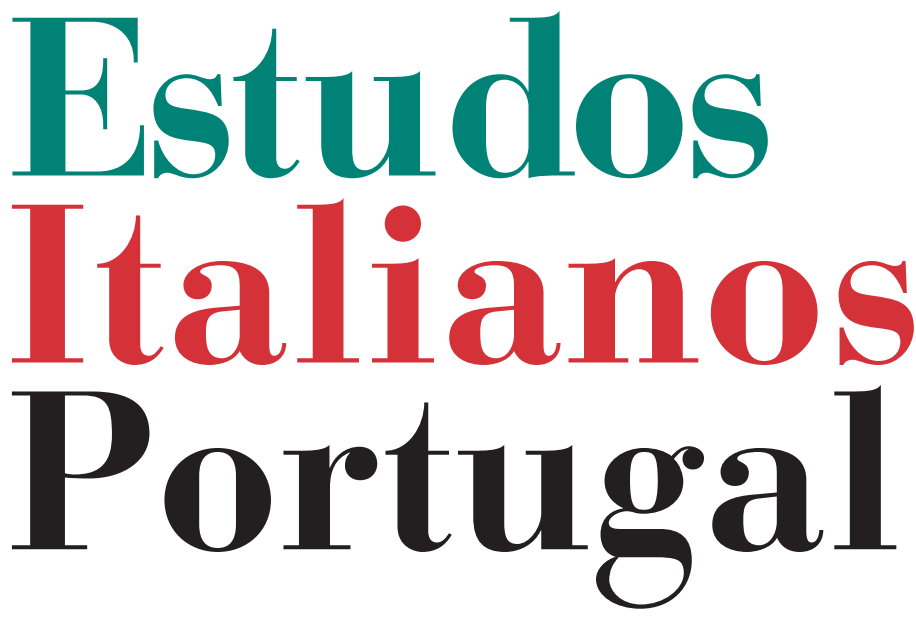

Instituto

Italiano

de Cultura

de Lisboa

Nova Série

No 12

2017 


\section{O SEMINÁRIO DE JESUS, MARIA E JOSÉ DE COIMBRA. UM PROJETO DE GIUSEPPE ANTONIO LANDI}

RuI LOBO*

GiUseppina RaGgi**

UM CONJUNTO DE CARTAS INÉDITAS

NA CORRESPONDÊNCIA trocada entre o astrónomo Giovanni Angelo Brunelli (1722-1804) e o botânico Ferdinando Bassi (1710-1774), ambos bolonheses, encontram-se algumas informaçôes que obrigam a reformular as hipóteses relativas à autoria do projeto do Seminário Diocesano de Coimbra. A principal novidade que essas missivas trazem é o testemunho da estada do arquiteto Giuseppe Antonio Landi (1713-1791) em Coimbra durante, pelo menos, quatro meses, de julho até novembro de 1751 . Efetivamente, no dia 20 de julho de 1751, Brunelli escreveu: "Ho mandato al Landi a Coimbra, dove è andato per una visita di una fabbrica, la lettera che mi inviate per lui"'. A notícia seguinte é datada de 23 de novembro de 1751, quando o astrónomo refere ao ami-

*Rui Lobo, doutorado pela Universidade de Coimbra (2010), é Professor no Departamento de Arquitetura da FCTUC e investigador do Centro de Estudos Sociais. Tem-se dedicado ao estudo da arquitetura dos séculos XVI a XVIII: arquitetura portuguesa, arquitetura universitária e arquitetura dos jesuítas. rlobo@uc.pt

**Giuseppina Raggi, doutorada em História da Arte pelas Universidades de Bolonha e de Lisboa (2005) é investigadora do Centro de Estudos Sociais da Universidade de Coimbra. Especialista da pintura de quadratura bolonhesa e sua difusão em Portugal e no Brasil, dedica-se atualmente à arquitetura colonial no Brasil e à atividade de Juvarra e dos Bibiena em Portugal. giuseppinaraggi@ces.uc.pt

${ }^{1}$ Carta de 20-07-1751, Archivio di Stato di Bologna, envelope "Lettere di Ferdinando Bassi”, s. n. 
go: "Il Landi è tornato da Coimbra, dove andò per una mia raccomandazione, e dove ha guadagnato non poco denaro"2. Alguns meses depois, a 21 de março de 1752, escreveu: "Già è arrivato il capo mastro del Landi col suo compagno" ${ }^{3}$. Na semana anterior, tinha referido a chegada em Lisboa do "Sig. Gian Carlo Bibiena colla moglie e compagni”" É É provável, por isso, que o mestre-de-obras de Giuseppe Antonio Landi tivesse viajado de Itália com o grande arquiteto-cenógrafo bolonhês e seus colaboradores.

O contexto geral destas notícias é a chamada de cientistas, arquitetos e artistas bolonheses por parte de D. João V e D. José I. Brunelli e Landi 5 tinham sido contratados para integrarem a expedição de demarcação de fronteiras do Brasil, na sequência do Tratado de Madrid, assinado a 13 de janeiro de $1750^{6}$. Ambos chegaram a Lisboa no dia 15 de setembro desse mesmo ano. A morte de D. João V, ocorrida pouco antes (a 31 de julho), obrigaria Brunelli e Landi a permanecerem três anos em Portugal - e é neste intervalo que se enquadram as cartas mencionadas ${ }^{7}$. Por outro lado, Giovanni Carlo Sicinio Bibiena (1717-1760) tinha sido escolhido por D. José

${ }^{2}$ Carta de 23-11-1751, ib.

${ }^{3}$ Carta de 21-03-1752, ib.

${ }^{4}$ Carta de 14-03-1752, ib.

${ }^{5}$ Sobre a obra de Giuseppe Antonio Landi ver Isabel Mayer Godinho Mendonça, Um álbum de desenhos dedicado a D. José I de Portugal. Uma atribuiçāo ao artista bolonhês Giuseppe Antonio Landi, Tese de Mestrado apresentada à FLUL, 1995, 2 vols.; id., António José Landi (1713/1791). Um artista entre dois continentes, Lisboa, Fundação Calouste Gulbenkian, 2003; e ainda Amazónia Felsinea. Antonio José Landi. Itinerário artístico e cientifico de um Arquitecto Bolonhês na Amazónia do Século XVIII, Lisboa, CNCDP, 1999.

${ }^{6}$ Jaime Cortesão, Alexandre de Gusmão e o Tratado de Madrid, Lisboa, Livros Horizonte, 1984; Luís Ferrand de Almeida, Alexandre de Gusmão, o Brasil e o Tratado de Madrid (1735-1750), Coimbra, INIC, 1990.

${ }^{7}$ A edição integral e comentada destas e de outras cartas encontra-se em fase de publicação por Giuseppina Raggi e Ângela Domingues. Ver também, sobre a estadia de Landi em Lisboa, Isabel Mayer Godinho Mendonça, Um álbum de desenhos, vol. 1, pp. 38-40. 
para projetar a Ópera do Tejo e os restantes teatros régios, obras pelas quais há muito se ansiava na corte ${ }^{8}$.

Embora Brunelli não cite explicitamente nem o Seminário de Coimbra nem o nome do 'mestre-de-obras de Landi', algumas evidências permitem associar o facto de Landi ter ganhado muito dinheiro em Coimbra com a revisão e remodelação do projeto da "fábrica" do seminário e a sua subsequente construção:

a) Um anterior mestre-de-obras de Landi, Giovanni Francesco Tamossi, tomou efetivamente conta da obra do seminário já com esta em andamento, sendo reconhecido (até agora) como o seu principal arquiteto. Tamossi havia colaborado com Landi na obra de remodelação da igreja de São Francisco de Cesena, em Itália, nos anos imediatamente anteriores (1749-1750) ${ }^{9}$.

b) Em 1751 a "fábrica" mais importante que estava a decorrer em Coimbra era, inequivocamente, a do seminário, cuja função concreta e simbólica requeria uma arquitetura adequada e atualizada (fig. 1).

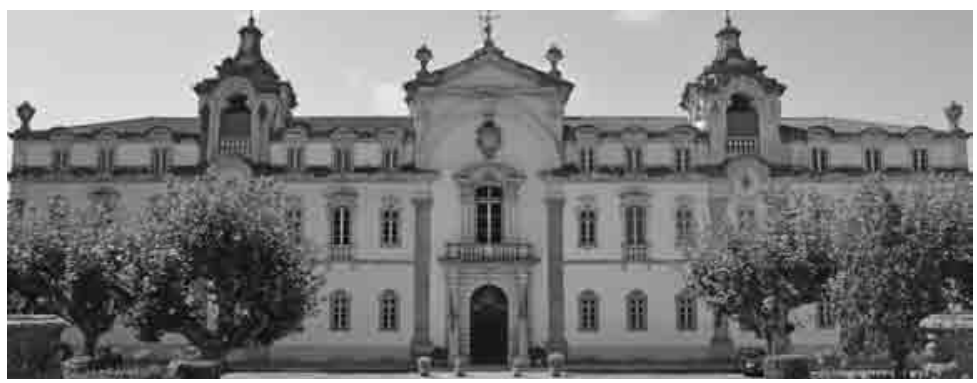

Fig.1 Seminário de Jesus, Maria e José de Coimbra: fachada principal (G.A. Landi e G.F. Tamossi, com ático acrescentado no século XIX). (C) Rui Lobo.

${ }^{8}$ Giuseppina Raggi, "Una lunga passione per l'opera in Portogallo: la regina-consorte Maria Anna d'Asburgo, l'arte dei Galli Bibiena e nuovi disegni per il Real Teatro dell'Ópera do Tejo", in Sabine Frommel, Micaela Antonucci (coord.), Da Bologna all'Europa. Artisti bolognesi in Portogallo (XVI-XIX secolo), Bologna, Bononia University Press, 2017, pp. 159-188. Sobre a Ópera do Tejo ver ainda Pedro Gomes Januário, Teatro Real de la Ópera del Tajo (1752-1755), Tese de Doutoramento apresentada à ETSAM/Universidade Politécnica de Madrid, 2008, 3 vols.

${ }^{9}$ Isabel Mayer Godinho Mendonça, António José Landi, pp. 116-117. 
c) O reitor do seminário, Nicola Giliberti, era de origem italiana (do reino de Nápoles) e demonstrou saber aproveitarse da rede de seus conterrâneos que, graças às políticas régias, estavam a chegar a Portugal. A presença em Lisboa de Giuseppe Antonio Landi representava uma oportunidade para o reitor. Brunelli intermediou o encontro. Como cónego que era, conhecera provavelmente Giliberti em Itália. Além disso, nas suas cartas, Brunelli descreve Landi como um arquiteto ambicioso, quer do ponto de vista artístico, quer do ponto de vista financeiro.

d) Giuseppe Antonio Landi manteria uma forte amizade com o reitor do seminário, Nicola Giliberti, como testemunha uma carta escrita pelo primeiro, de Belém do Pará, muitos anos mais tarde, e na qual se apresenta como "questo suo antico servitore", assinando "Suo umilissimo e obbligat. Servitore Antonio Giuseppe Landi" 10 .

e) A análise da linguagem arquitetónica do seminário evidencia a ligação com a cultura bolonhesa, nomeadamente na igreja (fig. 2 - cuja planta octogonal relembra a igreja de Santa Maria della Vita de Bolonha) e nas duas capelas internas, de Nossa Senhora da Anunciação (fig. 3) e de São Miguel (fig. 4).

Perante estes novos dados, a história do projeto do Seminário de Coimbra, em nossa opinião, terá de ser revista - passamos a resumi-la nas linhas que se seguem.

\section{1. ${ }^{\text {a }}$ FASE: O CONTRATO COM FREI JOĀo DA SOlEDADE E O INÍCIO DAS OBRAS}

Sabe-se, de acordo com dados revelados por Nelson Correia Borges e por Pedro Vieira Gomes, que o reitor do seminário,

\footnotetext{
${ }^{10}$ Carta de Landi para Giliberti, de 12-11-1776. Arquivo do Seminário de Coimbra, Pasta 24, Nicolau Giliberti, s. n. Transcrita em Giuseppina Raggi, Architetture dell'inganno: Il lungo cammino dell'illusione, Tese de Doutoramento, Univ. de Lisboa. Univ. di Bologna, 2005, Vol 2, pp. 1342-1343.
} 


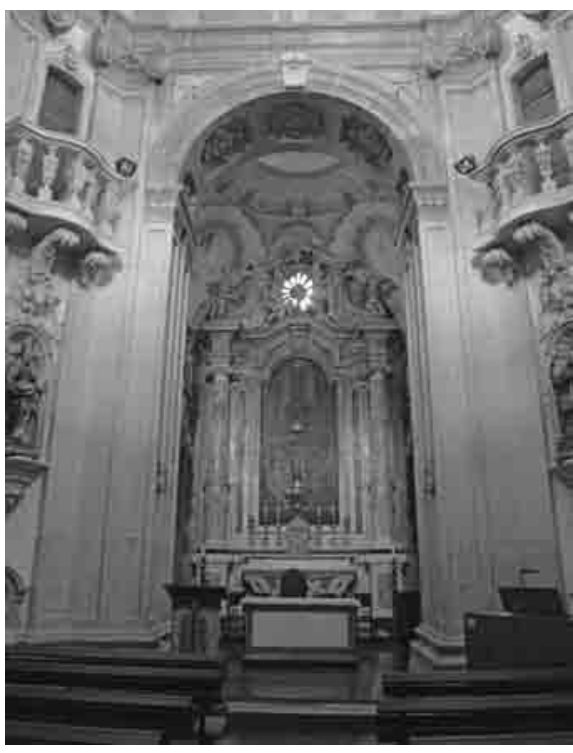

Fig. 2 Seminário de Coimbra: igreja octogonal (G.A. Landi e G.F. Tamossi); interior. (C) Rui Lobo.

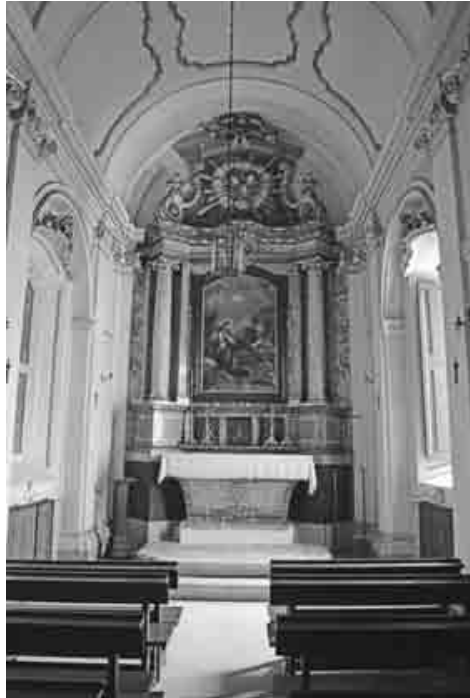

Fig. 3 Seminário de Coimbra: capela de Nossa Senhora da Anunciação (G. A. Landi e G. F. Tamossi). (C) Rui Lobo.

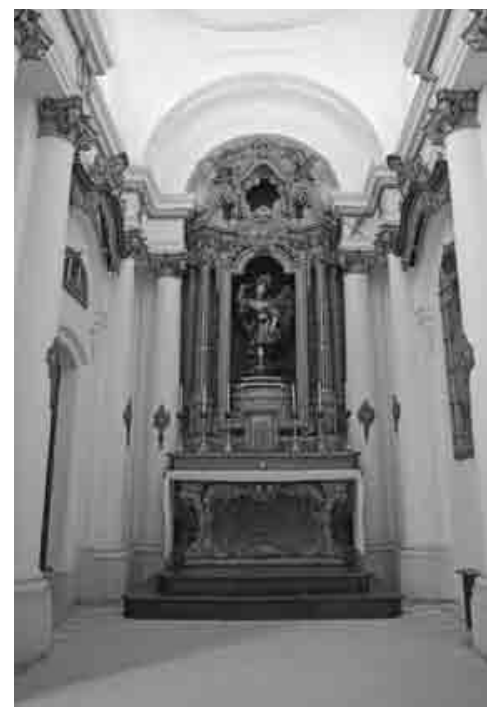

Fig. 4 Seminário de Coimbra: capela de São Miguel (G. G. Azzolini). (C) Rui Lobo. 
Nicola Giliberti, assinou um contrato de princípio com o arquiteto franciscano capucho frei João da Soledade e com o mestre-de-obras Manuel Rodrigues, em 11 junho de 1748, no sentido de se fazer a obra do "Colegio com Sua Igreja" para o Seminário de Coimbra, no sítio designado onde efetivamente se fez ${ }^{11}$.

A obra iniciou-se poucos dias depois, a 22 de junho de 1748, como mostra o Livro da hobra do Seminario, caderno manuscrito depositado no Arquivo do Seminário de Coimbra. O documento mostra o andamento das obras nos quatro primeiros anos, até finais de Novembro de 1751. A cerimónia de lançamento da primeira pedra, presidida pelo bispo-conde de Coimbra e grande mentor da obra, frei Miguel da Anunciação (1703-1779), realizou-se a 16 de julho de 1748 em cerimónia que contou com a presença do cabido da catedral e de algumas figuras da cidade ${ }^{12}$.

O andamento dos trabalhos até meados de 1751, altura em que Landi passou uma temporada em Coimbra, foi importante. Ainda assim não cremos que possa ter sido frei João da Soledade a desenhar o edifício que hoje vemos do seminário. Não se lhe conhecem outros projetos de calibre semelhante (Nélson Correia Borges apenas refere ser dele o desparecido Convento das Ursulinas de Pereira, atribuindo-lhe também o modesto Colégio de Santo António da Pedreira $\left.{ }^{13}\right)$. Por outro lado, o seminário é claramente obra de um arquiteto italiano

${ }^{11}$ Nélson Correia Borges atribuiu a autoria do projeto a frei João da Soledade: História da arte em Portugal. Do Barroco ao Rococó, Lisboa, Alfa, vol. 9, 1986, p. 27 [pp. 9-39]. O contrato, guardado no Arquivo da Universidade de Coimbra (Tab. Manuel Francisco dos Santos, Livro de Notas n. ${ }^{\circ} 14,19.11 .1747$ - 03.08.1748, fl. 135), foi revelado e parcialmente transcrito e publicado por Pedro Vieira Gomes, De Perpetuo Seminário. O Seminário de Jesus, Maria e José de Coimbra, Prova Final de Licenciatura em Arquitetura apresentada à FCTUC, 2002, pp. 95-97, 130-132.

${ }^{12}$ Arquivo do Seminário de Coimbra, Inventário do Seminário, dos bens móveis e de raiz, caderno manuscrito, fl. 9; Prudêncio Quintino Garcia, "Alguns apontamentos para a história do Seminário de Coimbra”, Instituiçōes Christãs, tomo V, 1. a s., 1887, p. 276.

\footnotetext{
${ }^{13}$ Nélson Correia Borges, cit., p. 27.
} 
ou italianizado. Neste sentido já se pronunciou Pedro Dias - "Não precisamos de dar mais exemplos para excluir qualquer ligação do barroco que se praticava em Coimbra com o Seminário Maior"14. Noutra ordem de razões, também nos parece (secundando uma opinião de Pedro Vieira Gomes) que conferir a autoria do seminário a Soledade, com base "somente num contrato, é pouco..." 15 .

Provavelmente, e numa primeira fase, avançou-se para a obra a partir de uma planta-base quadrangular proposta por frei João da Soledade. Parece-nos ser esta a explicação mais lógica e que pode justificar a atividade de preparação de terreno, de abertura de caboucos e de lançamento das fundaçôes que está documentada no referido Livro da hobra, para os anos de 1748,1749 e $1750^{16}$.

\section{2a fase: a temporada de Giuseppe Antonio Landi EM COIMBRA}

Como já referimos, Landi chegou a Lisboa em 15 de setembro de 1750. Formado como arquiteto na famosa Accademia Clementina, fora contratado como desenhador, juntamente

${ }^{14}$ Pedro Dias, "O Seminário Maior de Coimbra e as relações estéticas de Portugal com a Itália na Época Moderna”, Arquivo Coimbrão, 33-34 (1990-1992), 1994, p. 186 [pp. 175-197].

${ }^{15}$ Pedro Vieira Gomes, cit., p. 96.

${ }^{16}$ As obras desenrolaram-se continuadamente desde finais de junho de 1748 até inícios de novembro desse ano, registando-se ainda alguma atividade em dezembro e depois em janeiro de 1749, para se retomarem entre finais de fevereiro e meados de maio de 1749 . No entanto, praticamente pararam no resto do ano, excetuando alguma atividade registada em setembro. A atividade durante o ano de 1750 foi muito irregular: obras em janeiro e fevereiro, retomadas no final de abril e até finais de maio e depois praticamente um ano de inatividade (com exceção de um registo em agosto) até à "feria" de 12 de junho de 1751, data em que Landi já poderia estar em Coimbra; Regista-se a atividade de pedreiros, cabouqueiros, trabalhadores, rapazes, mulheres, carreiros - que trazem sobretudo areia, pedra, cal, água, tábuas. Há ainda pagamentos de pólvora, ao ferreiro e (em menor quantidade) ao tanoeiro e ao carpinteiro. Arquivo do Seminário de Coimbra, Livro da hobra do Seminario de JMJ, Als. 1-66v. 
com Brunelli (na qualidade de astrónomo e matemático), para fazer parte da já mencionada missão de demarcação de fronteiras do Brasil. O emissário da corte portuguesa em Itália, o carmelita João Álvares de Gusmão, recebera instruções para procurar técnicos de preferência em Bolonha, cidade dotada de uma universidade "em que têm florescido os estudos matemáticos" 17 .

Com o falecimento do rei, Landi ficaria retido na capital portuguesa em virtude do novo quadro político e do reajustamento dos objetivos da missão à América do Sul ${ }^{18}$. Foi neste contexto que se deslocou a Coimbra em meados de 1751 e que terá realizado um novo projeto para o seminário - edifício que estava em obra há três anos.

Landi esteve, pelo menos, quatro meses em Coimbra, entre julho e novembro de 1751 , sendo provável que tivesse viajado para esta cidade algum tempo antes. Curiosamente, o Livro da hobra do Seminario revela que no período imediatamente anterior o estaleiro estivera em crise. Não houvera obras desde finais de maio de 1750, com exceção de uma breve ocorrência em agosto ${ }^{19}$. A retoma continuada dos trabalhos parece, pois, coincidir com a estadia de Landi na cidade do Mondego - existem registos semanais justamente de junho a novembro de 1751, mês em que terminam os assentamentos do documento e no qual Landi retorna a Lisboa. Por outro lado, nos róis de trabalhadores, surgem novamente cabouqueiros (desde logo na "feria" de 12 de junho e, continuadamente, até à semana de 7 de agosto $^{20}$ ) o que mostra

${ }^{17}$ Isabel Mayer Godinho Mendonça, Um álbum de desenhos, vol. 1, pp. 38-40.

${ }^{18}$ Alexandre de Gusmão, secretário de D. João V e grande ideólogo do tratado, seria afastado pelo novo monarca D. José I, que nomeou Sebastião José de Carvalho e Melo como novo secretário de estado.

${ }^{19}$ Ver supra, n. 16. E ainda "Feria - 22 de Agosto de 1750": Arquivo do Seminário de Coimbra, Livro da hobra do Seminario de JMJ, fl. 65.

${ }^{20}$ Ib., fls. 66v-79v. Estes dados contrariam o que afirma Brito Cardoso, que refere que os cabouqueiros teriam deixado de aparecer em finais de 1750. António Brito Cardoso, "Novos dados para a história do Seminário Maior de Coimbra", Mundo da Arte, 11, 10-1982, p. 7 [pp. 2-7]. 
que ainda se faziam alterações ou acrescentos à implantação da obra e que esta se encontrava ainda numa etapa relativamente inicial ${ }^{21}$.

Outras referências interessantes, nesta fase, são os pagamentos continuados ao mestre da obra Manuel Rodrigues por conta "da empreitada da pedra lavrada do segundo corpo" e do que se lhe devia da "medição do primeiro corpo", o que sugere qua a construção avançava já ao longo de duas alas. Por outro lado, deram entrada no estaleiro grandes quantidades de pinheiro e de tijolo, o que dá a entender que se avançaria para as primeiras abóbadas, provavelmente no piso de entrada ${ }^{22}$.

A conjunção destes dados revela que partes do edifício estariam já lançadas e a avançar enquanto outras (onde se abriam os alicerces) ainda se (re)configuravam. Seria perfeitamente plausível, por exemplo, que o quadrângulo inicial estivesse já definido e que Landi acompanhasse a abertura das fundaçóes da nova igreja octogonal, certamente de sua autoria, no interior do pátio, junto da entrada. Julgamos que é um panorama deste tipo que tem de se admitir para o faseamento da construção do novo seminário.

\section{3. a Fase: a Vinda de Giovanni Francesco Tamossi}

Giuseppe Antonio Landi partiria para o Brasil a 2 de junho de $1753^{23}$. Antes, Giliberti - o sempre presente reitor do seminário - terá mandado vir de Itália (seguramente por sugestão de Landi) o mestre-de-obras João Francisco Tamossi. Documentos revelados anteriormente por Isabel Godinho Mendonça comprovam a relação profissional e de confiança

${ }^{21}$ A este primeiro Livro da hobra (o único que se conhece) certamente se seguiu outro, pois a construção só terminaria 14 anos mais tarde, como veremos.

${ }^{22}$ Arquivo do Seminário de Coimbra, Livro da hobra do Seminario de JMJ, fls. 66v ss.

${ }^{23}$ Isabel Mayer Godinho Mendonça, "Dados biográficos: Portugal e Brasil (17501791)”, Amazónia Felsinea, p. 47 [pp. 40-75]. 
entre Landi e Tamossi ${ }^{24}$. Era certamente Tamossi o capo mastro de Landi que estava em Lisboa em 21 de Março de 1752 (ainda antes da partida de Landi para o Brasil, portanto). A sua vinda teve um propósito que se torna agora mais claro: Tamossi deveria garantir a execução do projeto de Landi para o Seminário de Coimbra, face à ausência programada deste.

O primeiro documento conhecido que coloca Tamossi em Coimbra é apenas de finais de $1754^{25}$. Não obstante deve admitir-se que estivesse em Coimbra logo desde meados de 1752. Viria a cair de uma das torres do seminário (e o mestre-de-obras a falecer) em 6 de outubro de $1755^{26}$ - o que demonstra que o corpo da fachada estava já, nessa altura, bastante adiantado. Tamossi terá estado mais de três anos à frente da obra, nos quais esta avançou decisivamente.

Como intuiu Pedro Dias, "a traça geral do Seminário, bem como da igreja, parecem-nos demasiadamente boas para se poderem entregar a um mestre - e estamos em meados do

24 "No Archivio di Stato de Cesena encontrámos dois recibos referentes a pagamentos feitos ao arquitecto bolonhês - o primeiro, a 1 de Abril de 1749 [...] assinado por Giovanni Francesco Tamossi, que com ele provavelmente colaborava nas obras então em curso; o segundo datado de 30 de Janeiro de 1750, assinado pelo próprio Landi, referente à sua atividade nas obras realizadas durante o ano de 1749”. E mais à frente: "A presença de Giovanni Francesco Tamossi em S. Francisco de Cesena, provavelmente como colaborador de Landi, constitui o primeiro testemunho da sua atividade em Itália”, Isabel Mayer Godinho Mendonça, António José Land, pp. 116-117.

${ }^{25}$ Atestado da vistoria realizada por Tamossi ao Colégio Real de São Paulo, onde o próprio declara ser natural de Bolonha e ser mestre das obras do novo Seminário, datado de 17 de outubro de 1754. Francisco de Sousa Viterbo, Dicionário literário e documental dos arquitectos, engenheiros e construtores portugueses, Lisboa, Imprensa Nacional - Casa da Moeda, 1988, vol. 2, pp. 436-437 [reed. facsimilada da ed. 1904].

26 "Aos seis de outubro de 1755 annos, sem sacramentos, faleceo no Seminario de Jesus Maria Jose de huma torre abaixo do dito Seminario, que hé desta freguesia Joam Francisco Tamozi Mestre que hera das obras: enterrou-se o dia seguinte nesta Egreja de S. Pedro, e no dia seguinte se lhe fez na mesma Egreja officio de honras: de que fiz este assento, que assignei dia mez e era ut supra. O Prior Dr. José Rodrigues Mendes", Liv. dos defunct. de S. Pedro, fl. 226, excerto publicado em Prudêncio Quintino Garcia, Documentos para as biografias dos artistas de Coimbra, Coimbra, 1923 [ed. póstuma], pp. 224-225. 
século XVIII - que anda (e morre) em cima de andaimes; é trabalho claro de arquitecto, e bom, e não de um simples mestre-de-obras" ${ }^{27}$. Tamossi terá sido, efetivamente, o mestre-de-obras. $\mathrm{O}$ arquiteto, como agora sugerimos, só poderia ter sido Landi, de quem Tamossi fora colaborador próximo, poucos anos antes, em Cesena.

\section{4. ${ }^{a}$ FASE: A CONCLUSĀO DA OBRA POR Gian GiaCOMO AZZOLINI}

Como é amplamente conhecido, após a morte de Tamossi foi designado o também bolonhês Gian Giacomo Azzolini (1723-1791) para terminar a obra do seminário ${ }^{28}$. Azzolini, arquiteto, formado também na Accademia Clementina, estava já em Coimbra em 11 de fevereiro de $1756^{29}$, depois de ter colaborado na obra e nos cenários da Ópera do Tejo às ordens de Giovanni Sicinio Galli Bibiena ${ }^{30}$ - estrutura que ruiu com o grande terramoto de Lisboa, apenas sete meses após a sua inauguração.

O primeiro documento relativo à intervenção de Azzolini na obra do seminário é um Caderno de medição de pedraria, datado de 10 de maio de 1757, que este assinou conjuntamente com o mestre Manuel Rodrigues e que foi publicado por Pedro Vieira Gomes ${ }^{31}$. Não é clara a ocasião para a qual se fez a medição. Não é necessariamente o ponto a partir do qual Azzolini tomou cargo da obra, pois já se encontrava em

${ }_{27}$ Pedro Dias, cit., p. 182.

${ }^{28}$ Cirilo Volkmar Machado, Collecção de memórias relativa às vidas dos pintores, $e$ escultores, architectos, e gravadores portugueses, e dos estrangeiros, que estiveram em Portugal, Lisboa, Imp. de Victorino Rodrigues da Silva, 1823, pp. 190-191; Francisco de Sousa Viterbo, cit., vol. 1, pp. 84-86 [reed. facsimilada da ed. de 1899].

29 Sobre Azzolini ver Rui Lobo, "Gian Giacomo Azzolini (1723-1791): a Bolognese architect between Lisbon and Coimbra”, in S. Frommel-M. Antonucci (coord.) Da Bologna all'Europa. Artisti bolognesi in Portogallo (XVI-XIX secolo), pp. 203-226.

${ }^{30}$ Azzolini chegara a Lisboa em 1753, um ano após o arranque da obra da Ópera, juntando-se a Bibiena que havia sido seu professor na Accademia Clementina.

${ }^{31}$ Arquivo do Seminário de Coimbra, Caderno de medição de 1757, transcrito em Pedro Vieira Gomes, cit., 2002, pp. 101-128. 
Coimbra há mais de um ano - mas não devemos excluir essa hipótese. De qualquer modo, o documento dá uma ideia do que já estava feito, permitindo perceber o que fora realizado por Tamossi, de acordo com o projeto de Landi:

- As alas nascente, norte (da fachada) e poente, com as suas celas, portas e janelas, nos dois pisos acima da cota de entrada

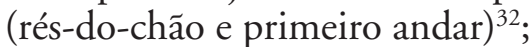

- $o$ arco de pedra (com junta fendida) da entrada principal do seminário, no corpo central da fachada ${ }^{33}$;

- a fachada do seminário até ao seu remate (incluindo o corpo central, as duas torres-campanário, as cimalhas e quatro fogaréus $)^{34}$;

- os dois imponentes portais clássicos (com pilastras rusticadas, em "bugnato") que dão acesso ao seminário, à esquerda e à direita do átrio de entrada (fig. 5) ${ }^{35}$;

- a igreja octogonal completa, até ao zimbório ${ }^{36}$, e incluindo o coro alto e a sacristia;

- os dois amplos lanços de escadas, à esquerda à direita da igreja, e respetivos arcos de entrada ${ }^{37}$;

32 "Segundo plano nas portas das sellas que cada vão faz $\mathrm{p}^{\text {os }}$ de Lançil 24 e são entre todos os vãos 36", ib., p. 101.

33 "O seu Portal Rustico na emtrada do portico faz de alto $20 \mathrm{p}^{\text {os }}$ e grosso 6 [...] importão 32.500”, ib., p. 113.

34 "Pella janella Principal na front ${ }^{\mathrm{a}}$ preço ajustado em cento e outenta e quatro mil reis 184.000"; "Pellas Armas de S. Exc a que vão sobre o dito portal trinta e cinco mil reis 35.000"; "Por cada Cupla das Torres da Simalha pa sima; Duzentos e setenta mil e duzentos reis e Ambas 540.400"; "Por cada fogareo e remate que vão em cima das pilastras e pilares da frontaria ajustados cada hum em dous mil reis e importão todos quatro 8.000", ib., p. 123.

35 "Os Dous Portais da Portaria se lhe avaleou cada hu em setenta mil reis e ambos importão 140.000 ”, ib., p. 122.

36 "Midição feita na Igreija principiando pella Capella mor", ib., p. 117; "Pello remate do zimbório quatro mil reis 4.000”, ib., p. 123.

37 "Da Midição nas escadas conventuais principiando do ultimo plano de sima $\mathrm{p}^{\mathrm{a}}$ baixo [...] cimcoenta e cinco degraos, que medidos se acha ter cada hum 2 varas que são dez Palmos e fazem varas 110 e dobradas pela outra escada que lhe comresponde fazem varas 220 [...] vem a importar [...] 247.500”, ib., p. 107. 


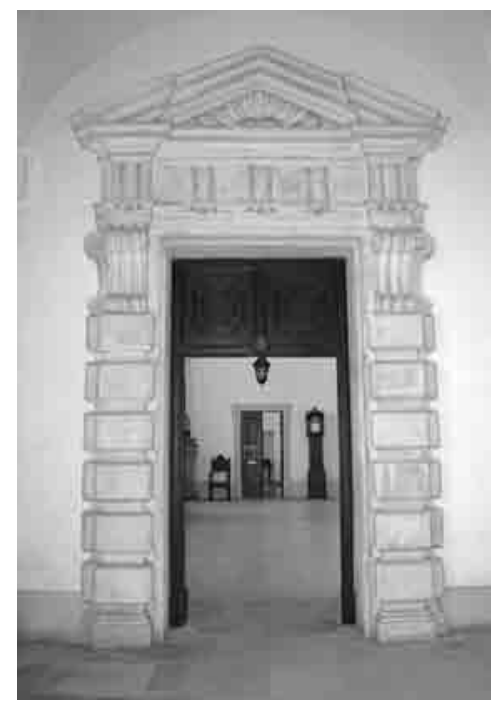

Fig. 5 Seminário de Coimbra: portal dóri- Fig. 6 Seminário de Coimbra: portal da

co do lado direito do átrio, com pilastras igreja, 1758 (G. G. Azzolini). rusticadas, em "bugnato" (G. A. Landi e (C) Rui Lobo.

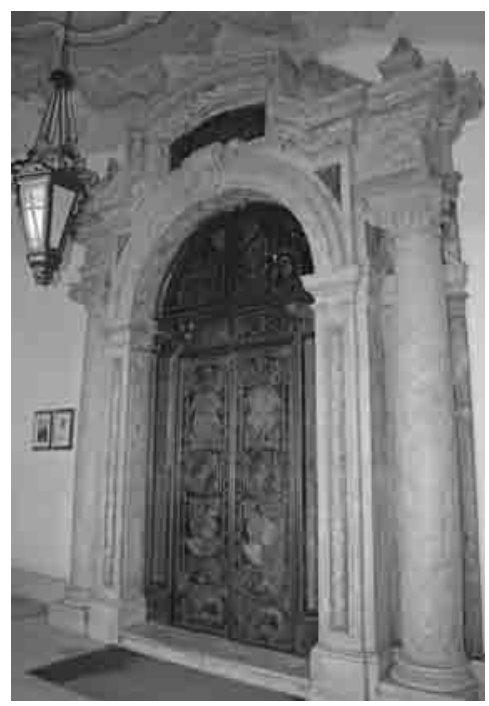

- a capela de Nossa Senhora da Anunciação, no andar superior, junto ao quarto destinado a "Sua Excelência" (o bispo $)^{38}$;

- a ala sul e traseira do seminário não tinha passado dos dois pisos da cave (o terreno desce neste sentido) ${ }^{39}$.

Daqui também se retira o contributo subsequente de Azzolini ${ }^{40}$ :

- Levantou os dois pisos principais da ala sul (ala traseira), incluindo a conclusão das duas escadas em espiral;

38 "Huma janella no Aratorio de S. Exc ${ }^{\text {[ }}$ [... 7.040", ib., p. 103; "Os Dous Portais que fazem (frente?) hum ao outro no tranzito do Aratorio de S. Exc a, se lhe avaliou cada hu em vinte e cinco mil reis e Ambos importão 50.000”, ib., p. 122.

39 "Medição que se fes no corpo da Parte de Baxo que se achava galgado ate o Nivel que corre da Frontaria pa Sul"; "Na frontaria pa a pte. Do Sul se achão quatorze janelas rusticas [...]; Por baixo destas ditas no Subterranio se achão nove [as atuais janelas oitavadas]", ib., pp. 124-125.

${ }^{40}$ Ver Rui Lobo, cit. 
- desenhou e fez a capela de São Miguel, junto ao ângulo sudeste, no primeiro andar;

- desenhou e fez o portal da igreja (fig. 6), que tem a data inscrita de 1758, e que se distingue claramente dos outros dois portais do átrio da entrada do seminário, desenhados por Landi;

- deve ser também Azzolini o autor do lavabo, junto de uma das escadas em espiral, à porta do antigo refeitório, na ala sul; em nossa opinião, é também dele a perspetiva arquitetónica ao fundo do corredor da ala poente, claramente da escola bolonhesa ${ }^{41}$.

Com a obra adiantada, mas ainda a decorrer, os primeiros seminaristas residentes entraram a 22 de setembro de 1758, data em que se fez a abertura oficial do seminário ${ }^{42}$. É deste período o Inventário dos bens móveis e de raiz, outro documento manuscrito pertencente ao Arquivo do Seminário de Coimbra ${ }^{43}$. A descrição dos espaços em funcionamento vem confirmar as alas do edifício já levantadas (norte, poente e nascente), bem como a existência da capela de Nossa Senhora da Anunciação, que surge já com este nome ${ }^{44}$. A igreja octogonal (já levantada) não estaria ainda aberta ao culto, nem é mencionada no inventário. Sabe-se

${ }^{41}$ A perspetiva, que tem sido atribuída ao pintor napolitano Pasquale Parente, é realizada a partir de um ponto de vista rebaixado (aumentando, assim, a monumentalidade da cena). Inclui uma escadaria em primeiro plano, desdobrando-se numa série de pátios exteriores sucessivos. A representação da escadaria, nos seus lanços laterais, não é bem conseguida, pelo que não se tem associado este trabalho a Azzolini. Já a sequência dos pátios em profundidade é bem executada e segue corretamente os modelos contemporâneos bolonheses.

${ }^{42}$ Arquivo do Seminário de Coimbra, Inventário do Seminário, dos bens móveis e de raiz, caderno manuscrito, fl. 9 .

${ }^{43} \mathrm{O}$ inventário foi aberto por D. Miguel da Anunciação em 1755, mas só com a entrada dos seminaristas começou a ser preenchido. Refere que "até ao presente se acha acabada metade da obra” (fl. 9). A construção, em si, estaria um pouco mais adiantada, como vimos.

${ }^{44}$ Arquivo do Seminário de Coimbra, Inventário do Seminário, fl. 9. 
que por esses anos Pasquale Parente pintava o fresco da $A s$ sunção e a apoteose da Virgem no teto da igreja, assinando-o em $1760^{45}$.

Azzolini acabaria por estar à frente da obra quase dez anos - foi este o tempo necessário para dá-la como concluída, o que veio a suceder em outubro de $1765^{46}$. Antes de regressar a Lisboa (para onde seguiria no ano seguinte como "Primeiro Arquiteto" dos teatros régios ${ }^{47}$ ) o arquiteto italiano faria ainda, a pedido de Giliberti, uma curiosa réplica, à escala, da igreja de Santa Maria do Loreto de Roma - que se colocou no terreiro em frente do seminário e que hoje, infelizmente, já não existe ${ }^{48}$.

\section{A arquitetura do Seminário de Coimbra e a encomenda ARTÍstica do REITOR NiCOla GiLIBERTI}

A chamada de Landi a Coimbra, na fase decisiva da obra do Seminário de Coimbra, encaixa perfeitamente na política posterior de encomenda artística a conterrâneos italianos do reitor Nicola Giliberti (1704-1783). Natural de Saponara (atual Grumento Nova), na Basilicata, antigo reino de Nápoles, foi secretário do núncio papal em Sevilha, onde estava em 1732. Quatro anos depois continuava por Espanha ${ }^{49}$. Não é claro como estabeleceu uma relação de amizade e confiança com D. Miguel da Anunciação, nem quando foi nomeado

${ }^{45}$ Vergílio Correia; António Nogueira Gonçalves, Inventário artístico de Portugal. Cidade de Coimbra, Lisboa, ANBA, 1947, p. 98.

46 "Dizem, que se concluiu em 28 de Outubro de 1765", Arquivo do Seminário de Coimbra, Sobre o Seminário Episcopal de Coimbra, manuscrito de António Inácio Coelho de Moraes, s. d., fl. 9.

${ }^{47}$ Sobre a atividade de Azzolini em Lisboa, ver novamente Rui Lobo, cit.

${ }^{48}$ A julgar pela planta de Coimbra de 1874, onde surge representada, teria uma planta de 5 metros de largura por 10 metros de profundidade, o que corresponderia provavelmente a uma réplica à escala 1:5 daquela igreja barroca de Roma, onde Giliberti professara.

${ }^{49}$ Prudêncio Quintino Garcia, "Alguns apontamentos para a história do Seminário de Coimbra” in Insituiçôes Christãs, tomo V, 2a s, 1887, pp. 56-57. 
reitor de uma primeira comunidade de seminaristas que o bispo, desde 1741, pusera a funcionar ${ }^{50}$.

Vimos já o recurso a arquitetos e mestres-de-obras bolonheses: Landi (provavelmente por intermédio de Brunelli), depois Tamossi (por intermédio de Landi) e finalmente Azzolini. Giliberti encomendaria ainda a Antonio Torregiani (filho do famoso arquiteto Alfonso Torregiani) o portão de ferro do átrio do seminário, importado de Bolonha por uma elevada soma de dinheiro; e a Pasquale Parente a pintura do teto da igreja, a que já aludimos. Encomendaria também de Itália o altar-mor e a porta de madeira da igreja (de Génova), as imagens dos altares laterais (ao escultor Gennaro Vassalo, de Nápoles) e o quadro do retábulo, do Menino Jesus entre os Doutores, do pintor bolonhês Giuseppe Varotti (ainda que esta peça não tenha sido a sua primeira escolha $)^{51}$.

A formação bolonhesa de Landi e de Azzolini (ambos formados na Accademia Clementina, como referimos ${ }^{52}$ ) garantiria uma certa unidade à arquitetura final. Ainda assim algumas diferenças podem detetar-se. Landi, através de Tamossi, é mais adepto do emprego das pilastras e de uma visão mais sintética da arquitetura, como se observa claramente na fachada do seminário ou nos interiores da igreja e da capela de Nossa Senhora da Anunciação. Já Azzolini evidencia um fazer arquitetónico mais cenográfico, como se pode ver no uso da brecha colorida do portal da igreja, que se destaca da alvura uniforme dos outros dois portais do átrio do seminário ${ }^{53}$

50 "Já em 1741 existiam defronte do Collegio dos Loyos em Coimbra umas casas que serviam de Seminario", ib, 1 $a_{S .}$, p. 243.

${ }^{51}$ Pedro Dias, cit. Ver ainda Giuseppina Raggi, Architetture dell'inganno, vol 1, pp. 733-747, vol 2, pp. 1336-1343. A atribuição da autoria é do Prof. Daniele Benati.

${ }^{52}$ Azzolini, dez anos mais novo, chegou a ser aluno de Landi. Foi também aluno de Giovanni Carlo Sicinio Bibiena na mesma escola. Por sua vez Landi e Bibiena haviam sido colegas, primeiro como alunos e depois como mestres.

${ }^{53} \mathrm{O}$ seminário encontrava-se originalmente dividido em duas partes, "huma para os Ordenandos, Exercitantes e Hóspedes, e a outra para os Seminaristas e Porcionistas". Arquivo do Seminário de Coimbra, Inventário do Seminário, fl. 9. 
desenhados por Landi e onde apenas se evidencia o rusticado das (recorrentes) pilastras. $\mathrm{Na}$ capela de São Miguel, o uso das colunas encostadas às paredes dá ao ambiente um caráter mais plástico e dinâmico, que não está em sintonia estilística com o tipo de solução adotado na igreja e na outra capela.

Questão importante, já apontada por Pedro Vieira Go$\mathrm{mes}^{54}$, tem a ver com a não conformidade entre as janelas do ático atual e o desenho da restante fachada do seminário. Com efeito, aquelas parecem ser claramente um acrescento ao projeto original. Não é plausível que Landi, Tamossi ou Azzolini concebessem semelhante remate para a frontaria, com janelas de recorte neoclássico (alternando remates em frontão triangular e curvo), totalmente distintas das fenestrações de desenho barroco do restante alçado, dispensando a presença de uma cornija cimeira sobre toda a frente do edifício.

Deve considerar-se, inclusivamente (e a nosso ver), que todo o piso superior atual, ao nível do segundo andar, terá sido acrescentado. De facto, nunca aparece referência a um segundo andar na documentação mais antiga consultada, nem no Caderno de medição de 1757 , nem no Inventário dos bens móveis e de raiz de 1758-1761, tão pouco no texto manuscrito de António Inácio Coelho de Moraes. Duas descrições, de inícios e de meados do século XIX, parecem confirmar que o imóvel apenas apresentava dois pisos principais. António Moniz Barreto Corte-Real afirmava, em 1831 que "A fachada do Edifício está repartida em duas ordens de janelas" 55 e que "O edifício é quadrado. Tem da parte do sul quatro andares, e dos outros lados três, exceptuando a frontaria, que tem dous, por estar edificado numa ladeira" ${ }^{56}$. Simões de Castro, em 1867, refere-se ao seminário nos mes-

\footnotetext{
${ }^{54}$ Pedro Vieira Gomes, cit., pp. 80-82 e desenhos 13-14.

${ }^{55}$ Ib., p. 178.

${ }^{56}$ António Moniz Barreto Corte-Real, Bellezas de Coimbra, Coimbra, Real Imprensa da Universidade, 1831 , p. 178 e nota a).
} 
mos termos ${ }^{57}$. Não obstante, ambos os pares de escadas, as principais (a cada lado da igreja) e as em espiral (da ala traseira), teriam já os mesmos degraus que têm hoje. Dariam certamente acesso a terraços (junto das torres, por exemplo) e/ou a águas furtadas.

Por outro lado, sabe-se que ocorreram obras importantes no rescaldo de uma epidemia de gripe ocorrida em $1863^{58}$, durante o bispado de D. José Manuel de Lemos (18581870). Também D. Manuel Bastos Pina (1872-1913) ordenou reformas profundas no edifício ${ }^{59}$. Deve atribuir-se a estas campanhas o acrescento de um novo piso superior (em data anterior às primeiras fotografias conhecidas do seminário, onde surgem sempre as atuais janelas altas da fachada ${ }^{60}$ ). Sabe-se ainda que a cor original do edifício era vermelha ${ }^{61}$.

\section{Conclusão}

Restará fazer, por fim, uma derradeira e decisiva pergunta: é sustentável atribuir a autoria do projeto do Seminário de Coimbra a Giuseppe Antonio Landi com base na comparação estilística com outras obras deste arquiteto? A resposta não poderá deixar de ser afirmativa.

57 "Por ser em declive o terreno sobre que assenta, não apresenta o edifício a mesma altura nas suas quatro faces: tem na fachada principal dois andares, três nas lateraes e quatro na posterior", Augusto Mendes Simões de Castro, Guia histórico do viajante em Coimbra e arredores, Coimbra, Imprensa da Universidade, 1867, p. 117.

${ }^{58}$ Aurélio de Campos, Seminário de Coimbra, Coimbra, 2014, pp. 174-175.

${ }^{59} \mathrm{Ib}$., pp. 182, 193: "Os corredores do último andar [...] não tinham a altura nem a ventilação e luz que hoje possuem. O Prelado [D. Manuel Bastos Pina] mandou levantar los corredores e quartos, mudar todo o travejamento e ferro do tecto e abrir portas e janelas".

${ }^{60}$ Foi no bispado de D. Manuel Bastos Pina e em resposta ao grande afluxo de seminaristas que se construíram os dois blocos quadrangulares a um lado e outro da fachada: a "Casa Nova" (inaugurada em 1876, à esquerda) e a "Casa Novíssima" (inaugurada em 1883, do lado direito), ib., p. 192. Este prelado ordenaria ainda a construção do jardim de entrada e respetivos muros.

${ }^{61}$ Pedro Dias, cit., p. 180. 
São pouco significativas as primeiras intervenções arquitetónicas de Landi em Itália, no curto período de tempo em que aí esteve ativo. A melhor referência será, talvez, a sua reconhecida produção gráfica de arquitetura (desenhos e álbuns). Desta, podemos referir o conjunto de desenhos que realizou para as portas da cidade de Bolonha ${ }^{62}$, alguns dos quais apresentam semelhanças evidentes (desde logo no uso de pilastras rusticadas em "bugnato") com os dois portais executados por Tamossi, a um lado e outro da portaria do seminário.

Da sua vasta obra arquitetónica realizada em Belém do Pará, no Brasil ${ }^{63}$ (posterior à sua estadia em Portugal), poderemos chamar a atenção para a capela octogonal de São João Baptista ${ }^{64}$, composição muito semelhante (desde logo em planta) à da igreja do Seminário de Coimbra. Deveremos sobretudo destacar a composição do corpo central da fachada da igreja de Sant'Ana (fig. 8) ${ }^{65}$ que apresenta evidentes afinidades com a composição do corpo central da fachada do seminário (fig. 7). Em ambos os casos (na igreja de Sant'Ana e no seminário), podemos verificar a repetição do motivo do arco apoiado em pilastras, enquadrando a entrada ${ }^{66}$, encimado por um frontão sóbrio e elegante, que remata superiormente o conjunto.

A breve referência a estas obras brasileiras, associada à documentação inédita que acima sistematizamos, permite afir-

${ }^{62}$ Ver Maria Delbianco, Silvia Meade, "Desenhos para as portas da cidade de Bolonha”, Amazónia Felsinea, pp. 92-109 (e em particular o projeto para a Porta San Mamolo, p. 103).

${ }^{63}$ Onde é conhecido como António José Landi. Na verdade Landi assinava dos dois modos; Giuseppe Antonio ou Antonio Giuseppe.

${ }^{64}$ Mário Barata, "Landi na arquitetura do Grão Pará e influxo do tardo-barroco italiano”, Amazónia Felsinea, pp. 246-257.

${ }^{65}$ Importa notar que as torres não faziam parte da composição original - são uma adição do século dezanove. $I b$., pp. 246-252. Consta que Landi estará sepultado nesta igreja.

${ }^{66}$ Ainda que na igreja de Sant'Ana as pilastras estejam por detrás de colunas avançadas em relação ao plano da fachada. 
mar, sem grandes sobressaltos, que Giuseppe Antonio Landi é o mais óbvio arquiteto do Seminário de Coimbra. E que o Seminário de Coimbra é, muito provavelmente, a única obra de arquitetura construída que reflete a fugaz passagem de Landi por Portugal.

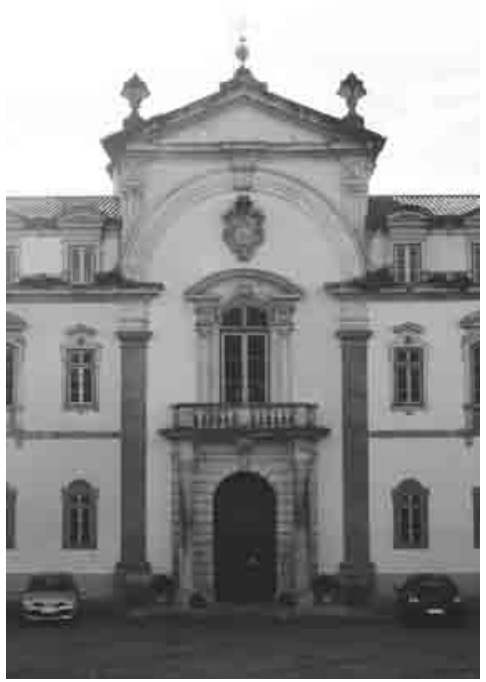

Fig. 7 Seminário de Coimbra: corpo central da fachada (G. A. Landi e G. F. Tamossi). (C) Rui Lobo.

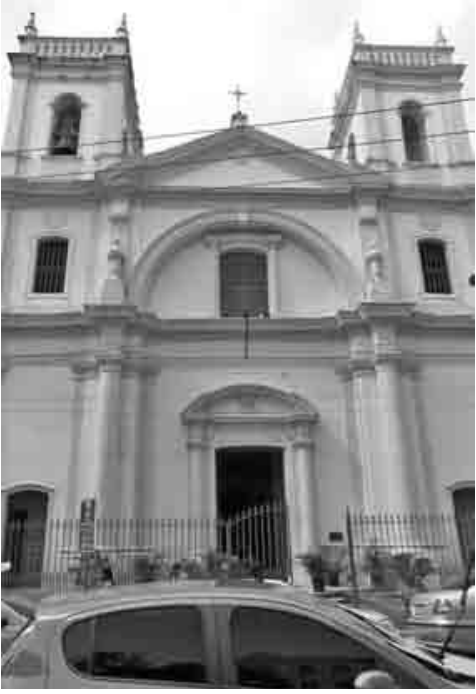

Fig. 8 Igreja de Sant'Ana, Belém do Pará: corpo central da fachada (G. A. Landi) com torres adicionadas no século XIX. (C) Rodrigo Rolim Santos/Panoramio. 